\section{FABIANO GONTIJO}

[ORG.]

\section{(c) creative commons}

Direção editorial: Ana Kelma Gallas

Diagramação: Kleber Albuquerque Filho

Editor OMP: Eliezyo Silva

Imagem da capa: Karine Gallas

\section{ABEC}

A, ARASIL

doi) 5 crossref

\section{LESTU PUBLISHING COMPANY}

Editora, Gráfica e Consultoria Ltda

Avenida Paulista, 2300, andar Pilotis Bela Vista, São Paulo, 01310-300, Brasil.

(11)97415.4679 | editora@lestu.org | www.lestu.com.br
FICHA CATALOGRÁFICA

Dados Internacionais de Catalogação na Publicação (CIP)

\section{G641 GONTIJO, Fabiano}

Corpo, sexo, gênero: estudos em perspectiva / Fabiano Gontijo (Org.). - São Paulo, SP: Lestu Publishing Company, 2021.

\section{3 p. online}

ISBN: 978-65-996314-2-9

DOI: https://doi.org/10.51205/lestu.978-65-996314-2-9

1. Identidade de Gênero. 2. Teoria Queer. 3. Sexualidade. 4. Corpo. 5. Sociologia. I. Autor(a). II. Título. III. Lestu. IV.

CDD: 306.7

1. Gênero e sexualidade: Aspectos sociais: Sociologia: 306.7

\section{CORPO, SEXO, GÊNERO}

\section{ESTUDOS EM PERSPECTIVA}




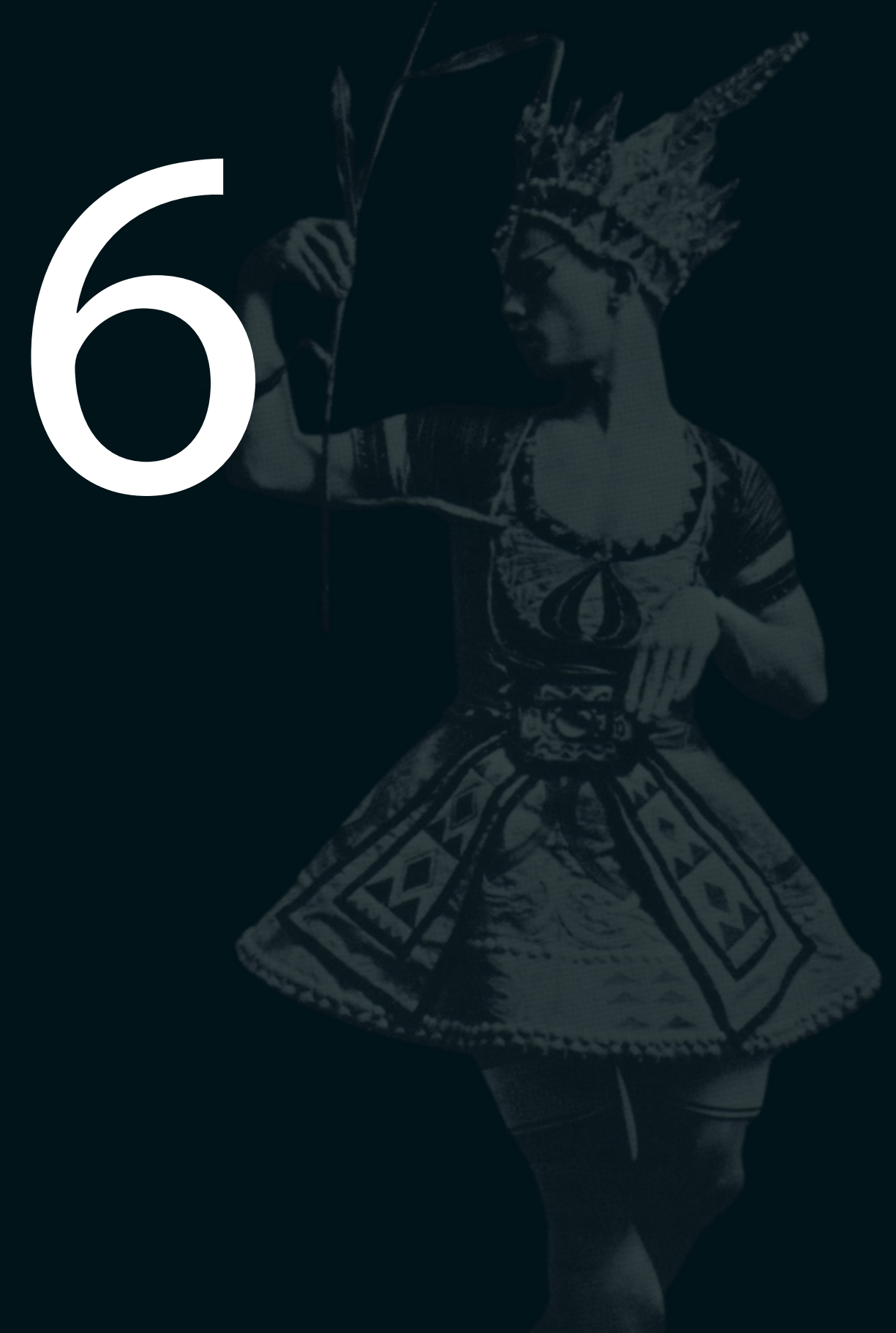




\section{0 aprofundamento da vulnerabilidade social de mulheres e pessoas LGBT+ em decorrência da pandemia de COVID-19}

Jullyane Alves Teixeira

Mariana Cavalcante Moura

Thátila Thaira Ferreira da Silva Porto

\section{Introdução}

A pandemia causada pela contaminação do novo coronavírus (SarsCoV-2), agente causador da doença classificada como síndrome gripal COVID - 19, alterou e vem alterando substancialmente as dinâmicas de vida, trabalho, cuidado, interação social, renda, sobrecarga de serviços domésticos e situações de violência na sociedade em todo o mundo. As implicações da crise sanitária surgida no final do ano de 2019 pela disseminação generalizada do referido vírus são tão complexas que diversos estudos vêm atribuindo a esse acontecimento uma nova nomeação. Para muitos, estamos a viver não somente uma pandemia, mas na verdade um processo de "sindemia", conceito que acopla a designação pandemia + sinergia, para identificar fenômenos que tem determinada condição epidemiológica intensificada por fatores de ordem cultural, social, econômica e social:

A palavra epidemia designa uma enfermidade em gera contagiosa e de caráter transitório, que ataca simultaneamente um grande número de indivíduos em um espaço geográfico limitado. Para designar uma epidemia em escala planetária, usa-se a palavra pandemia. Em segundo lugar, a palavra sindemia. Ela encerra o conceito criado pelo antropólogo-médico estadunidense Merrill Singer,

1 Mestra pelo Programa de Pós-Graduação em Sociologia da UFPI - jullyane@ufpi.edu.br. Lattes: http://lattes.cnpq.br/6233265423855790

2 Mestranda pelo Programa de Pós-Graduação em Sociologia da UFPI - advmarianamoura@gmail.com. Lattes: http://lattes.cnpq.br/9274973684049251

3 Mestranda pelo Programa de Pós-Graduação em Sociologia da UFPI - thatilaporto@gmail.com. Lattes: http://lattes.cnpq.br/4158174984629770

4 Artigo: Covid-19 não é pandemia, mas sindemia: o que essa perspectiva científica muda no tratamento. Disponivel em: https://cee.fiocruz.br/?q=node/1264. Acesso em 08 de set. 2021. 
na década de 1990, para designar as combinações sinérgicas entre a saúde de uma população e os respectivos contextos sociais, econômicos e culturais, aí incluídos os recursos disponíveis (hospitais, ambulatórios, medicamentos, especialistas etc.). (VEIGA NETO, 2020)

É importante ressaltar que a invocação aqui dessa classificação, que tem objetivado compreender a extensão dos impactos desse fenômeno, se dá justamente porque é a partir de um entendimento da conjunção de fatores que colaboraram para a catarse de acontecimentos que fizeram com que estejamos vivendo a maior crise do séculoXXI, e é somente através de um olhar abrangente, caleidoscópico, que teremos condições de pensar as alternativas de superá-la (Veigas Neto, 2020). Assim, a primeira consideração que precisa ser observada para se compreender como um fenômeno do campo da saúde criou e vem criando tantas afetações, passa por compreender a disparidade de acesso a bens, serviços e direitos, das pessoas ao redor do mundo. A partir disso veremos que os impactos dessa "sindemia" não atingiram da mesma maneira todas as pessoas no planeta. A população que vive sob as condições previstas nos piores índices socioeconômicos, por exemplo, teve seus índices de vulnerabilidade social acentuados no período. Assim, muitos dos discursos difundidos popularmente que surgiram nesse período como "estamos todos no mesmo barco" ou "a pandemia teve por finalidade igualar todas as pessoas, uma vez que ricos ou pobres, homens ou mulheres, estão à mercê da mesma doença" não se configuram na realidade. Contudo, mesmo dentro da população mais pobre e com trabalhos mais precarizados, alguns marcadores sociais se destacaram, como gênero, sexualidade e raça.

Um exemplo evidente disso se apresenta quando verificamos que o período imposto de distanciamento social asseverou o quadro de violência de gênero já existente, gerando um enorme desafio para pessoas vulneráveis à violência intrafamiliar ou doméstica, sejam elas mulheres, especialmente as negras, ou pessoas $\mathrm{LGBT}+{ }^{5}$, pois a maioria provavelmente teve sua mobilidade reduzida, o que acabou resultando em permanecer na mesma residência ou

5 Este artigo utiliza o termo "LGBT", por ser o mais comumente utilizado nos estudos e manuais sobre o tema no país, adotado após a I Conferência Nacional GLBT no Brasil, contudo, é sabido que existem variantes que integram a sigla. Por esse motivo, acrescentamos o sinal gráfico de " + " para especificar que temos conhecimento disso e queremos englobar as demais formas de expressão da sexualidade que, ou ainda não são definidas por consenso ou ainda estão sendo compreendidas pela comunidade científica e ativistas. A I Conferência Nacional GLBT, ocorrida no dia 08 de junho de 2008, promovida pelo Governo Federal da época, envolvendo mais de 10 mil pessoas em conferências estaduais e 1.200 delegados/as nacionais, reunidos em Brasília, decidiu pelo uso da terminologia LGBT para identificar a ação conjunta de lésbicas, gays, bissexuais, travestis e transexuais, no Brasil. Posteriormente, em dezembro de 2008, no maior evento do movimento LGBT do Brasil, o Encontro Brasileiro de Lésbicas, Gays, Bissexuais, Travestis e Transexuais EBLGBT, também se decidiu pelo uso do termo LGBT (ABGLT, 2010). sob subordinação/dependência que o seu agressor ${ }^{6}$, perdendo, muitas vezes, sua rede de apoio.

Portanto, além do surgimento de uma nova doença, que devastou muitas famílias e segue causando direta ou indiretamente altos índices de mortalidade, parte significativa da população ainda lida com o agravamento dos problemas da violência de gênero e/ou doméstica.

Dessa forma, iremos analisar pesquisas publicadas em 2020/2021, que apresentam dados acerca dos índices de violência de gênero contra mulheres e pessoas LGBT+, bem como o impacto que a pandemia de COVID-19 teve nessa população, inclusive em relação ao mercado de trabalho.

\section{Violência contra a mulher: fatores e histórico}

A violência contra a mulher se configura, segundo a ONU Mulher, como um fenômeno generalizado, ou seja, que também pode ser caracterizado como uma pandemia.

Assim como os índices de violência contra pessoas LGBT+ no Brasi e no mundo, todos os anos, atingem níveis absurdos. Esse tipo de violência doméstica por si acontece porque histórica e culturalmente as ações de homens e mulheres tendem a ter relevância e valores diferenciados na sociedade, o que faz com que muitos acreditem que existe um gênero que tem direto a, de fato, ter domínio e poder sobre o outro. A colonização do ser feminino e a dominação masculina (BOURDIEU, 2002) fazem parte da construção dessa estrutura social onde homens se julgam superiores e controladores das vontades das mulheres, o que pode acabar culminando na violência contra as mesmas quando estas não se dobram à vontade deste homem. Essa violência doméstica pode chegar a níveis extremos e acabar em feminicídio. Juridicamente, o feminicídio é classificado como um homicídio qualificado, ou seja, é um tipo de homicídio que tem sua pena aumentada vez que causado por motivo vil, covardia, ódio. Sociologicamente, o feminicídio é um crime que tem suas bases nas relações de poder e nas estruturas de opressão às mulheres, que acabam por questionar a condição política, social e econômica de todas as escolhas que a mulher faz. Se relaciona ainda com o apagamento e o menosprezo de tudo que ela é ou representa, levando-a à morte, além de física, simbólica. Quando ocorre um feminicídio em uma sociedade patriarcal, machista e misógina, a pessoa (geralmente um homem que tinha alguma relação da ordem familiar ou afetiva com a

6 Devido a centralização de poder masculino nas relações de gênero, o termo agressor especificado parte de todo um acúmulo de entendimento, significados, literatura e legislações que tem apresentado a realidade significativa de homens que praticam violência da ordem doméstica e familiar como expressão da manutenção da ordem de gênero estabelecida. (CONNELL \& PEARSE, 2015) 
mulher) que praticou este ato, é diretamente responsável pelo crime, mas o Estado, também, é responsabilizado indiretamente (ROMINI, 2019) por esse feminicídio, pois vivemos em uma sociedade alicerçada nas bases patriarcais, onde o machismo e a misoginia estão imbricados nas ações cotidianas, tanto que na maioria das vezes não são perceptíveis.

Em pesquisa recente, o 14으 Anuário da Segurança Pública (2020), revelou que $66,6 \%$ das vítimas de feminicídio no país eram negras, o que reforça a extrema situação de vulnerabilidade socioeconômica e a violência que este grupo populacional está submetido. A maior parte dos casos se concentra em mulheres em idade reprodutiva, cerca de $56,2 \%$ das vítimas de feminicídio tem entre 20 e 39 anos. Nos casos onde a informação está disponível, verificou-se que 58,9\% dos feminicídios ocorreram na própria casa e em $89,9 \%$ dos casos o autor do crime é o próprio companheiro ou ex-companheiro da vítima, que, em 53,6\% dos casos, utilizam-se de armas brancas para perpetrar o crime, seguido de armas de fogo $(26,9 \%)$ e outros meios $(19,5 \%)$, como agressão física e asfixia mecânica (SOBRAL; PIMENTEL; LAGRECA, 2020).

Apesar de muitas pessoas conhecerem a Lei Maria da Penha, algumas mulheres não acreditam que a vida delas pode mudar caso acessem a lei, muitas sentem vergonha, medo de denunciar e acreditam que denunciando podem correr mais risco de morte (EVANGELISTA, 2018). A falta de acolhimento e estrutura para atender essas mulheres, a escassez de delegacias especializadas, o julgamento da família e da sociedade, que muitas vezes culpabiliza as mulheres pela violência sofrida, são a causa para essa desconfiança na efetividade das denúncias. Acrescido a isso, a dependência financeira, psicológica e emocional, tornam esses crimes ainda mais cruéis, haja vista a dificuldade que essas vítimas encontram de sair da situação de violência e o descaso do estado em desenvolver políticas públicas de prevenção efetivas.

\section{Violência contra a mulher e a pandemia de coronavírus}

Uma pesquisa do Instituto Datafolha encomendada pelo Fórum Brasileiro de Segurança Pública - FBSP (2021), intitulada "Visível e Invisível - A vitimização de mulheres no Brasil", que já está na sua 3a edição, foi divulgada em junho desse ano, e apontou que uma em cada quatro mulheres acima de 16 anos afirma ter sofrido algum tipo de violência no último ano no Brasil, ou seja, durante a pandemia, o que revela que cerca de 17 milhões de mulheres $(24,4 \%)$ sofreram violência física, psicológica ou sexual no último ano. Importante frisar que, ainda que essa porcentagem represente estabilidade em relação à última pesquisa, de 2019 , quando
27,4\% afirmaram ter sofrido alguma agressão, é preciso que se analise o local onde essas agressões foram realizadas. As agressões dentro de casa aumentaram de $42 \%$ para $48,8 \%$ ao tempo que as agressões na rua diminuíram de $49 \%$ para $19 \%$. Em se tratando da violência contra mulheres acima de 50 anos, por exemplo, cresceu a participação de filhos e enteados nas agressões. Esse fenômeno demonstra não haver uma violência doméstica apenas conjugal, mas uma violência intrafamiliar. Agora, entre os autores de violência, além dos companheiros (25\%) e ex-companheiros $(18 \%)$, aparecem pais e mães (11\%), padrastos e madrastas (5\%), filhos e filhas (4\%).

Nos dois primeiros meses de pandemia, esses dados da Datafolha/ FBSP (2021) mostraram também um aumento na taxa de feminicídios no Brasil. A pesquisa foi realizada em 12 estados brasileiros e a média de aumentos de casos de feminicídios no país cresceu $22,2 \%$ entre março e abri de 2020 , em relação ao mesmo período de 2019 . Ao mesmo tempo, houve uma queda nos registros de lesão corporal dolosa em decorrência de violência doméstica. Alguns dos motivos que podem ter levado a essa queda, não se deve a não ocorrência das agressões, mas à subnotificação dos casos, tendo em vista a maior dificuldade em se registrar as agressões, já que o agressor passou a ficar mais tempo com a vítima, além das próprias medidas de isolamento social, que tornaram o acesso aos locais de denúncia mais difíceis, desde a disponibilidade de transporte público até o funcionamento das próprias delegacias, vez que muitas tiveram redução ou então suspensão do atendimento presencial. Ainda segundo dados da pesquisa, os motivos apontados pelas mulheres que mais pesaram para a ocorrência da violência que vivenciaram foram a perda de emprego e, por consequência, da renda e impossibilidade de trabalhar para garantir o próprio sustento (25\%) e a maior convivência com o agressor (22\%). Menos de $10 \%$ citou dificuldade de ir à delegacia como fator para o aumento de vulnerabilidade. No entanto, a pesquisa não abarcou todas as realidades, de modo que não se pode fazer uma comparação com a situação de mulheres que vivem na cidade e no campo de forma acrítica.

A precarização das condições de vida é maior entre aquelas que sofreram violência: $62 \%$ das mulheres vítimas afirmaram que a renda familiar diminuiu. Entre as que não sofreram violência esse percentual foi de $50 \%$. Além disso, $47 \%$ das mulheres que sofreram violência também perderam o emprego. A média entre as que não sofreram violência foi de $29,5 \%$. As mulheres negras, entre pretas $(28,3 \%)$ e pardas $(24,6 \%)$, foram mais agredidas que mulheres brancas $(23,5 \%)$, demonstrando a disparidade racial entre mulheres que sofrem violência. 0 estudo também 
destaca que são as mulheres separadas e divorciadas que têm níveis mais elevados de vitimização (35\%), em comparação com casadas (17\%), viúvas $(17 \%)$ e solteiras (31\%). Isso ocorre porque a tentativa de rompimento com o agressor pode aumentar as chances de as mulheres serem mortas. Ou seja, a separação é, ao mesmo tempo, uma tentativa de interrupção da violência, mas também o momento em que ela fica mais vulnerável.

Os dados do Relatório de Criminalidade (2020) da Secretaria de Segurança Pública do Piauí corroboram com os resultados da pesquisa do FBSP, visto que as denúncias e acionamento do botão do pânico aumentaram 20,96\%. No entanto, as denúncias registradas em boletins de ocorrência nas Delegacias Especializadas de Atendimento à Mulher DEAM, diminuíram durante todo o ano, o que pode ter a ver com o fato de que há poucas cidades que possuem DEAMs no estado, ao tempo que $83 \%$ dos feminicídios ocorreram em cidades do interior.

Assim, as medidas de distanciamento social e o medo de contaminação tem feito com que a mulher em situação de violência doméstica não realize a denúncia. Isso pode ocorrer, tanto pelo medo de se contaminar ao sair de casa durante o trajeto para realizar a denúncia (o que não precisa ocorrer, posto que ela pode fazer denúncia pelos meios virtuais, no entanto muitas não têm conhecimento ou acesso a essas tecnologias), além do medo de ficar desassistida emocional ou financeiramente num período incerto como o que vivemos.

\section{O impacto da pandemia de coronavírus no mundo do trabalho para as mulheres}

A pesquisa "Sem Parar: o trabalho e a vida das mulheres na pandemia", elaborada pela Gênero e Número e a Sempreviva Organização Feminista (2021), demonstrou que a pandemia impactou profundamente a vida e o trabalho das mulheres, não apenas nas situações de violência doméstica, no mundo do trabalho os desafios das mulheres também foram intensificados no período. $O$ estudo analisou os efeitos da pandemia e do isolamento social sobre o trabalho, a renda das mulheres e a sustentação financeira, contemplando o trabalho doméstico e de cuidado realizado de forma não remunerada no interior dos domicílios.

Os resultados demonstram que as mulheres apresentam as maiores taxas de desemprego e um acúmulo de funções, tanto entre as que têm remuneração, como aquelas que não tem trabalho remunerado, mas que também acumulam mais carga de trabalho doméstico e cuidados com outras pessoas, como filhos e parentes. O estudo concluiu que $50 \%$ das mulheres brasileiras passaram a cuidar de alguém na pandemia. Das mulheres que passaram a se responsabilizar pelo cuidado de alguém, $52 \%$ eram negras; $46 \%$ brancas e $50 \%$ indígenas. No caso das mulheres rurais esse percentual alcança $62 \%$ das entrevistadas. A pesquisa indica como as desigualdades raciais e de renda marcam a vida e o trabalho das mulheres na pandemia, assim como a diversidade de experiências de mulheres rurais e urbanas.

Mesmo as mulheres que seguiram trabalhando durante a pandemia com manutenção de salários, $41 \%$ afirmaram trabalhar mais na quarentena, e $40 \%$ afirmaram que a pandemia e a situação de isolamento social colocaram a sustentação da casa em risco. A pesquisa aponta ainda que a organização do cuidado ancorada principalmente na exploração do trabalho de mulheres negras e no trabalho não remunerado das mulheres é um modelo que leva ao fracasso na busca de redução das desigualdades antes e durante a pandemia do coronavírus.

Além disso, as relações entre trabalho e atividades domésticas se imiscuíram ainda mais, e se antes pagar por serviços era a solução possível para algumas, a pandemia mostrou a intensificação do trabalho das mulheres como um todo. Elas trabalham mais porque as tarefas ainda não são distribuídas igualmente no ambiente doméstico. Entre tantas dimensões de desigualdades evidenciadas neste período, a sobrecarga de trabalho doméstico e de cuidado foi uma das questões que as mulheres sentiram logo que as medidas de isolamento social foram iniciadas nos municípios brasileiros.

\section{Violência contra as pessoas LGBT+ e a pandemia de coronavírus}

Ao longo da história, o movimento LGBT+ tem lutado arduamente para equiparar direitos civis e sociais no mundo inteiro e também em nosso país? . Embora tenha avançado bastante nas últimas décadas, essa é uma batalha que ainda não foi vencida. Percebe-se que boa parte da sociedade e do Congresso Nacional persiste tentando impor seu modo de ser e pensar sobre pessoas que querem viver sua sexualidade sem ter que passar por humilhações ou pagar com a vida. Contudo, é importante questionar: por que tal violência e discriminação persistem? Como é de se esperar, não existe resposta simples para essa pergunta, no entanto, é possível refletir que certamente a desinformação e incompreensão

7 Sobre o assunto, ver: Devassos no Paraíso, 4ae ed., 2018, de João Silvério Trevisan, uma das obras mais completas na literatura nacional. 
dos conceitos que permeiam o gênero e as sexualidades contribuem bastante para essa situação. É inquestionável o quanto avançamos em diversos aspectos, mas também é possível perceber que este cabo de guerra vive sob constantes oscilações.

Em relação às pessoas $\mathrm{LGBT+}$, os dados mais recentes relacionados à violência contra essa população, realizado pelo Grupo Gay da Bahia em parceria com a ONG Acontece Arte e Política LGBTI+, de 2020, registrou a ocorrência de 237 mortes violentas de LGBT+ no Brasil. Foram 224 homicídios (94,5\%) e 13 suicídios (5,5\%). A pesquisa revelou o aumento das mortes de travestis e mulheres transexuais em relação a 2019, quando foram registradas 161 mortes de travestis e mulheres transexuais (70\%), um número que demonstra a vulnerabilidade dessa população. Foram registradas ainda as mortes de 51 gays (22\%), 10 lésbicas (5\%), 3 homens transexuais (1\%), 3 bissexuais (1\%) e 2 homens heterossexuais confundidos com gays $(0,4 \%)$.

No entanto, observou-se uma redução das mortes violentas de pessoas LGBT+, em comparação com 2019, uma queda de $28 \%$. A pesquisa identificou 215 homicídios $(90,7 \%)$, seguido de 13 suicídios $(5,4 \%)$ e 9 latrocínios $(3,7 \%)$. Quanto à causa da morte, predominam as mortes violentas com arma de fogo $(42,3 \%)$, seguido de armas brancas $(23 \%)$ e espancamento $(9,1 \%)$.

Quanto ao perfil das vítimas, 33\% tinham entre 15 e 30 anos e $8 \%$ tinham mais de 46 anos, 5 vítimas eram menores de idade. 0 levantamento identificou 74 pardos e pretos (54\%) e 62 brancos (46\%) entre os que morreram. O relatório aponta ainda que o Nordeste ocupa o primeiro lugar em número de mortes com 113 casos, seguido do Sudeste com 66, depois, vêm as regiões Norte e Sul com 20 mortes cada. No Centro-Oeste foram registradas 18 mortes. Os municípios mais violentos foram Fortaleza (20 casos), São Paulo (10 casos), Belo Horizonte e Manaus (com 6 casos cada), seguidos de Natal e Salvador (com 5 casos cada).

Outro dado relevante observado foi em relação à ocupação das vítimas, o relatório demonstrou que 44,66 \% eram profissionais do sexo, seguidos de cabeleireiros/as $(10,67 \%)$, professores/as $(8,73 \%)$, autônomos/as $(2,91 \%)$, entre outros. Segundo o relatório, esse dado reflete "o grau de exclusão e violação de direitos básicos como saúde, educação e cultura para uma ampla parcela da comunidade LGBTI+ brasileira, sobretudo, das travestis e pessoas transgêneros" (MOTT et al, 2021). O relatório chama atenção ainda que:
Em 2020, apesar de registrar-se um número de mortes (homicídios, suicídios e latrocínios) significativamente menor que o ano anterior (2019), alerta-se para a subnotificação e os efeitos provocados pela pandemia do Novo Coronavírus (SARS-CoV-2 - severe acute respiratory syndrome coronavirus 2) que intensificou ainda mais o isolamento de muitos LGB $\mathrm{TI}+$, tendo em vista que dada população já era impactada pela falta de sociabilidades, referências e espaços. (MOTT et al, 2021, p.10)

É fato que a pandemia reduziu a mobilidade de grande parcela dos brasileiros que foram obrigados a seguir as medidas obrigatórias de contenção da doença, incluindo o isolamento social, que indica aos grupos sociais em geral a permanecerem em suas residências, salvo população que trabalha com serviços essenciais. Parte da população LGBT+ vive situações familiares difíceis, o que os coloca em posições ainda mais vulneráveis, seja com a necessidade de conviver com uma família LGBTfóbica ou com a necessidade de sair de casa, por conta dos conflitos. O relatório alerta ainda para o fato de que:

Apesar da redução quantitativa, ressalte-se que não existem motivos reais e factíveis para se comemorar, a redução no número de mortes motivadas pela LGBTIfobia não se deu pelo incentivo do Estado na promoção de políticas públicas de inclusão e proteção desse segmento, mas sim, por uma oscilação numérica imponderável e pela enorme subnotificação identificada durante as buscas, pesquisas e registros e também pelo desmonte - a partir de 2018 - dos investimentos em políticas públicas, campanhas de incentivo à denúncia e proteção às vítimas. (MOTT et al, 2021, p.10)

Em janeiro de 2021, no mês da Visibilidade Trans, a Associação Nacional de Travestis e Transexuais - ANTRA, lançou o Dossiê dos Assassinatos e da Violência Contra Pessoas Trans Brasileiras (2021), relativos aos dados de 2020, que apontou que o Brasil continua sendo o país que mais mata travestis e transexuais no mundo. $O$ país passou do 55이 lugar de 2018 para o 68o em 2019 no ranking de países seguros para a população LGBT+. Somente nos dois primeiros meses de 2020, o Brasil apresentou aumento de $90 \%$ no número de casos de assassinatos de 
pessoas trans em relação ao mesmo período de 2019. Em 2019, foram 20 casos no mesmo período, enquanto em 2020 foram 38 notificações, o maior índice dos últimos quatro anos. O dossiê aponta a contradição de que durante a pandemia do COVID-19, os índices de assassinato de pessoas LGBT+ diminuiu, como aconteceu com outras parcelas da população, pela necessidade do isolamento social colocado em muitas cidades/estados.

No entanto, ao contrário do esperado, o assassinato de pessoas trans aumentou, revelando um cenário onde os fatores sociais se intensificaram e tem impactado a vida das pessoas trans, especialmente as travestis e mulheres transexuais trabalhadoras sexuais, que seguem exercendo seu trabalho nas ruas para ter garantida sua subsistência, uma vez que a maioria não conseguiu acesso às políticas emergenciais do estado devido a precarização histórica de suas vidas.

Os dados apresentados no Dossiê da ANTRA (2021) não refletem exatamente a realidade devido à subnotificação do estado, assim como a ausência de dados governamentais, o que, na concepção da ANTRA, demonstra que o Brasil vem passando por um processo de recrudescimento em relação à forma com que trata travestis, mulheres transexuais, homens trans, pessoas transmasculinas e demais pessoas trans. Esse panorama reforça a importância do trabalho de monitoramento, incidência política e denúncias a órgãos internacionais que a ANTRA realiza, que desde seu início, tem se firmado como uma importante ferramenta na construção de dados e proposição de elementos que irão impactar a forma de combate à violência transfóbica em nossa sociedade.

A ANTRA (2021) denuncia ainda que mesmo diante desse cenário e da constante cobrança por parte dos movimentos sociais, não houve nenhum projeto específico de apoio à população LGBT+ para o enfrentamento da pandemia e os dados apresentados. Os dados encontrados pela pesquisa, além de denunciarem a violência, explicitam a necessidade de políticas públicas focadas na redução de homicídios de pessoas trans, em especial para a proteção das trabalhadoras sexuais, que representam $90 \%$ da população trans, assim como o acesso as políticas de assistência, e outros fatores que colocam essa população como o principal grupo que tem suas existências precarizadas, expostas a diversas formas de violência, e a mortes intencionais no Brasil.

Apesar de alarmantes, os números apresentados nas pesquisas citadas possivelmente são maiores, tendo em vista que nem todas as agressões culminam em atendimento médico de urgência e emergência ou registros de ocorrências criminais. Além disso, mesmo quando há denúncias nos órgãos judiciais, é grande o número de subnotificações, quando essas agressões caem na vala de crimes de agressão comum, sem que se dê nome a elas. É preciso enfatizar ainda, em relação aos dados sobre pessoas LGBT+, que a maioria dos dados que temos no Brasil não são oficiais, pois o governo não criou mecanismos eficazes para mapear essas informações, sendo, tais dados, resultados de estudos independentes de grupos e associações que defendem direitos dessa população.

O Coletivo \#VotelGBT divulgou, em 2020, uma pesquisa onde avalia o impacto da pandemia na vida dessa população. A pesquisa online ouviu 10 mil pessoas de todos os estados, com maior proporção de respostas na Região Sudeste. Os dados, que foram analisados por pesquisadores da Universidade Federal de Minas Gerais - UFMG e da Universidade Estadual de Campinas - UNICAMP, mostram que há desigualdades entre as LGBT+ que envolvem acesso à saúde, renda e trabalho, e, inclusive, exposição ao coronavírus. O IVLC - Índice de vulnerabilidade LGBT+ à Covid-19 - mede os diferentes níveis de risco e impacto da doença para a saúde, renda e trabalho entre LGBT+ de acordo com a raça, orientação sexual e identidade de gênero. Pessoas trans e LGBT+ negros e indígenas apresentam os maiores índices de vulnerabilidade (Vote LGBT, 2020). Os dados sobre vulnerabilidade das pessoas transexuais corroboram com o que foi encontrando na pesquisa elaborada pela ANTRA (2021), citada anteriormente.

A pesquisa divulgada (Vote LGBT, 2020) aponta que os três maiores impactos que a pandemia trouxe para a população LGBT+ foram: piora na saúde mental, afastamento da rede de apoio e falta de fonte de renda. Os casos de depressão, ansiedade e estresse vêm aumentando na população geral devido à pandemia. Para a população LGBT+, que já é atingida com maior frequência por essas condições, o efeito sobre a saúde mental é ainda maior. Mais da metade (54\%) dos participantes afirmaram estar precisando de apoio psicológico. Levando-se em conta o contexto de marginalização dessas pessoas no âmbito familiar e em outras esferas do convívio social, como escola ou trabalho, as redes de apoio se tornam especialmente importantes. Para $16,6 \%$ das pessoas entrevistadas, o maior impacto sentido da crise sanitária são as novas regras de convívio social, como o distanciamento, e para $11,7 \%$ é a solidão. O estudo mostra que a solidão afeta mais drasticamente pessoas mais velhas, de 45 a 54 anos ou acima dos 55 , do que os mais jovens, de 15 a 24 anos. 


\section{O impacto da pandemia de coronavírus no mundo do trabalho para as pessoas LGBT+}

Os crimes de ódio contra pessoas LGBT+, além de constituírem desrespeito aos direitos humanos não ocorrem apenas sob a forma de homicídios e agressões físicas, mas também por atos de violência moral e psicológica, que acabam culminando em abandono e exclusão familiar, evasão escolar, precarização do trabalho, comprometimento da saúde mental, entre outros. Essas violências não se dão de forma isolada, mas se reproduzem em diversas esferas sociais, provocando a estigmatização e a marginalização do indivíduo LGBT+. Apesar dos casos brutais, culminados em mortes, terem mais visibilidade, não devemos esquecer que a discriminação possui múltiplas facetas, visto que a violência é exercida de diversas formas, por exemplo, agressões simbólicas e verbais que tentam infiltrar uma ideia de imoralidade e desqualificação dos indivíduos por conta de sua orientação sexual ou identidade de gênero.

É fato que o trabalho é um marcador social importante para todas as populações ao longo da história, no entanto, se torna vital para as que foram - e continuam sendo - historicamente marginalizadas. As pessoas LGBT+ fazem parte desse escopo, posto que sua situação de exclusão social se propaga desde o abandono escolar até o mercado de trabalho mais precarizado ou, pior ainda, como no caso das travestis e transexuais: mais de $90 \%$ se prostituem por não conseguir empregos (ANTRA, 2021). As dificuldades de acesso ao mercado de trabalho para a população LGBT+ durante a pandemia se tornou ainda maior, muitas pessoas LGBT+ perderam a renda de forma imediata sem o acesso ao trabalho formal, o que afetou diretamente sua capacidade de sobreviver.

A taxa de desemprego na população LGBT+ no período analisado foi de $21,6 \%$, segundo a pesquisa da Vote LGBT (2020), índice bem maior do que para a população geral, que chegou a 12,6\% em abril/2020. Uma em cada 5 pessoas LGBT+ não possui nenhuma fonte de renda individual hoje, enquanto 1 em cada 4 perderam emprego em razão da Covid-19. Quase metade $(44,3 \%)$ das pessoas LGBT+ que responderam ao questionário tiveram suas atividades totalmente paralisadas durante $\mathrm{o}$ isolamento. Cerca de $10,6 \%$ dos participantes indicaram a falta de dinheiro como sua maior dificuldade durante o isolamento social, enquanto a falta de trabalho foi apontada por $7 \%$. Outro fato interessante e frequente revelado pela pesquisa foi o sentimento de alívio de algumas pessoas que adotaram o home office (trabalho virtual), por não precisarem mais frequentar o ambiente de trabalho. O sentimento positivo está relacionado à pausa no convívio com colegas e até culturas de empresas LGBTfóbicas que se transformam em locais hostis e inseguros no dia a dia (Vote LGBT, 2020).

\section{Considerações finais}

Os dados apresentados demonstram, sem dar margem a dúvidas, que a situação de vulnerabilidade de mulheres e pessoas LGBT+, seja nos espaços sociais e familiares, assim como no mercado de trabalho, têm piorado em razão da pandemia, ou como apontado na introdução, sindemia, de COVID-19. Outrossim, eles salientam que é preciso se atentar ao fato de que não é possível olhar para a situação de mulheres e pessoas LGBT+, seja na pandemia ou fora dela, de forma genérica e sem se atentar para os indicadores sociais e econômicos, como se todas essas pessoas estivessem sujeitas às mesmas vulnerabilidades. Existem corpos que carregam marcadores sociais que se traduzem em experiências, vivências e oportunidades distintas. Para entender como se dão essas experiências que apontam vantagens ou desvantagens sociais a partir desses marcadores, é preciso debruçar-se sobre a questão considerando a inter-relação entre raça, classe, gênero, orientação sexual, nacionalidade, capacidades físicas, etnia, faixa etária, entre outros fatores.

Nesse sentido, mulheres e pessoas LGBT+ que vivem em ambientes violentos e inseguros e tem seu cotidiano marcado ainda por sobrecarga, pobreza e precariedade, precisam mais do que discursos abstratos e propostas apenas emergenciais com prazos pré-determinados, mas sim de políticas públicas efetivas, pensadas em agendas que tenham alcance imediato e de longa duração que garantam acesso a emprego e renda, proteção social, educação, saúde e saneamento básico. Discussões que aliem propor condições básicas de equiparação de direitos que se atrelem não apenas às condições econômicas, mas também às que possibilitam romper com as estruturas de opressão que continuam incidindo e perpetuando as desigualdades.

No caso de mulheres, para além das garantias de acesso à educação e trabalho formal equânimes, é preciso se atentar ao trabalho doméstico e de cuidados como fundamental para se entender suas condições de vida, bem como, no caso de pessoas LGBT+, a busca por possibilitar ambientes familiares e sociais que garantam a permanência saudável dessas pessoas na família, escola, mercado de trabalho e sociedade. Essas questões são imprescindíveis num contexto em que se busca um projeto de sociedade justa e igualitária. 


\section{Referências}

ABGLT - Associação Brasileira de Lésbicas, Gays, Bissexuais, Travestis e Transexuais. Manual de Comunicação LGBT. Curitiba: ABGLT, 2010. Disponível em: https://unaids.org.br/wp-content/uploads/2015/09/ Manual-de-Comunica\%C3\%A7\%C3\%A3o-LGBT.pdf. Acesso em 09 set. 2021.

AGÊNCIA PATRÍCIA GALVÃO. Violência Contra a Mulher Avança com Coronavírus na América Latina. [S.I]. [2020]. Disponível em: https:// agenciapatriciagalvao.org.br/violencia/violencia-contra-a-mulheravancacomcoronavirus-na-america-latina/?print=pdf. Acesso em: 14 abr. 2021

ANTRA (2021). Dossiê dos assassinatos e da violência contra pessoas TRANS no Brasil em 2020. Disponível em: <https://antrabrasil.files. wordpress.com/2021/01/dossie-trans-2021-29jan2021.pdf> Acesso em: 18 ago. 2021

BOURDIEU, Pierre. A Dominação Masculina. 2. Ed. Rio de Janeiro: Bertrand Brasil, 2002.

CONNELL, Raewyn; PEARSE, Rebecca. Gênero: uma perspectiva global. São Paulo: Nversos, 2015.

EVANGELISTA, lanara Silva. Cê vai se arrepender de levantar a mão pra mim: rotas críticas de mulheres que romperam o ciclo de violência doméstica. 2018197 f. Dissertação (Mestrado em Sociologia) - Centro de Ciências Humanas e Letras. Universidade Federal do Piauí, 2018.

Fantástico. Exclusivo: Número de feminicídios cresce durante a pandemia do coronavírus no Brasil. Disponível em: https://g1.globo.com/fantastico/ noticia/2020/05/31/exclusivo-numero-de-feminicidios-cresce-durantepandemia-do-coronavirus-no-brasil.ghtml. Acesso em: 21 Ago. 2021.

Fórum Brasileiro de Segurança Pública e Instituto Datafolha. Visível e invisível: a vitimização de mulheres no Brasil. 3ạ ed. 2021. Disponível em: https://forumseguranca.org.br/wp-content/uploads/2021/06/relatoriovisivel-e-invisivel-3ed-2021-v3.pdf. Acesso em: 21 Ago. 2021

Gênero e Número e Sempreviva Organização Feminista. Sem parar: o trabalho e a vida das mulheres na pandemia. Disponível em: http:// mulheresnapandemia.sof.org.br/wpcontent/uploads/2020/08/Relatorio Pesquisa_SemParar.pdf. Acesso em: 27 Ago. 2021

Observatório de Mortes Violentas de LGBTI+ no Brasil - 2020: Relatório da Acontece Arte e Política LGBTI+ e Grupo Gay da Bahia; /Alexandre Bogas Fraga Gastaldi; Luiz Mott; José Marcelo Domingos de Oliveira; Carla
Simara Luciana da Silva Ayres; Wilians Ventura Ferreira Souza; Kayque Virgens Cordeiro da Silva; (Orgs). 1. ed. Florianópolis: Editora Acontece Arte e Política LGBTI+, 2021. Disponível em: https://grupogaydabahia.files wordpress.com/2021/05/observatorio-de-mortes-violentas-de-Igbti-nobrasil-relatorio-2020.-acontece-lgbti-e-ggb.pdf Acesso em: 19 mai. 2021.

ROMIO, Jackeline Aparecida Ferreira. Sobre o feminicídio, o direito da mulher de nomear suas experiências. Revista Plural, v. 26, n. 1, p. 79-102 2019.

SOBRAL, Isabela; PIMENTEL, Amanda; LAGRECA, Amanda. Retrato dos feminicídios no Brasil em 2019: análise dos registros policiais. In: $14^{\circ}$ Anuário de Segurança Pública, p. 118 - 122. Ano 2020. Disponível em https://forumseguranca.org.br/wp-content/uploads/2020/10/anuario-14 2020-v1-interativo.pdf. Acesso em: 13 set. 2021.

TREVISAN, João Silvério. Devassos no Paraíso: a homossexualidade no Brasil, da colônia à atualidade. 4. a ed. Rio de Janeiro: Objetiva, 2018.

VEIGA NETO, Alfredo. Mais uma lição: sindemia covídica e educação. In Educação \& Realidade. Seção temática: as lições da pandemia. Revista da Faculdade de Educação da Universidade Federal do Rio Grande do Sul. ISSN 0100-3143 (impresso) e 2175-6236 (online). Disponível em: https:// seer.ufrgs.br/educacaoerealidade/article/view/109337. Acesso em 10 Set. 2020.

VOTE LGBT. Diagnóstico LGBT+ na pandemia. Junho, 2020. Disponível em https://static1.squarespace.com/static/5b310b91af2096e89a5bc1f5/t/5e f78351fb8ae15cc0e0b5a3/1593279420604/\%5Bvote+lgbt+\%2B+box1824 \%5D+diagno\%CC\%81stico+LGBT\%2B+na+pandemia_completo.pdf Acesso em: 08 jun. 2021 